\section{Research Article}

(c) 2021 Nwosu et.al.. This is an open access article licensed under the Creative Commons Attribution-NonCommercial 4.o International License (https://creativecommons.org/licenses/by-nc/4.o/)

Received: 27 October 2020 / Accepted: 17 December 2020 / Published: 5 March 2021

\title{
Teacher Self-Concept and its Association with Willingness to Include Children with Special Needs in Regular Classes: Teacher Empathy as a Mediator
}

\author{
Kingsley Chinaza Nwosu ${ }^{1}$ \\ WP Wahl ${ }^{2}$ \\ Hasina Cassim³
}

Elizabeth Ifeoma Anierobi ${ }^{4}$

\author{
Chioma Christiana Akuneme 5
}

\section{Emmanuel Nkemakolam Okwuduba ${ }^{6}$}

${ }^{1}$ Postdoctoral Research Fellow, Division of Student Affairs, University of the Free State, South Africa

${ }^{2}$ Director: Student Life, University of the Free State, South Africa

3 Department of Early Childhood Education, University of Venda, South Africa

${ }^{4}$ Department of Educational Foundations, Nnamdi Azikiwe University, Awka, Nigeria

${ }^{5}$ Department of Educational Foundations, Nnamdi Azikiwe University, Awka, Nigeria

${ }^{6}$ Doctoral Student, Department of Mathematics and Science Education,

$$
\text { University of Malaya, Malaysia }
$$

DOI: https://doi.org/10.36941/jesr-2021-0029

\section{Abstract}

More appealing is the inclusive education practice that recognizes diversity among children than practices that lead to inequality in education. However, there have been implementation challenges including the rejection of children with special needs (CWSNs) in regular classes by teachers. Given this, the study attempted to build an empirical model to explain associations between teacher self-belief system and socio-emotional factors and their willingness to include CWSNs in their classes. The sample size consisted of 316 teachers. Using path analysis, findings showed, among others, that the conceptual model fit the data satisfactorily, and that teacher self-concept had direct effects on teachers' willingness to include CWSNs in their regular classes. Teacher cognitive selfconcept was a better predictor and its impact was significantly mediated by teacher empathy. It was concluded that willingness for inclusion could be influenced by teacher belief system and socio-emotional characteristics.

Keywords: self-concept, teacher empathy, inclusion, special needs

\section{Introduction}

The global trend in the education of children with special needs (CWSNs) is their inclusion in regular classes (Imaniah, \& Fitria, 2018). Although the inclusion of special needs individuals into normalised environments enjoys more prominence in the current body of literature, it is important to note that historically this idea is also supported by theoretical frameworks such as Feuerstein's (2006) Mediated 
Learning Experience and Structural Cognitive Modifiability. This inclusion of CWSNs is geared towards giving them equal rights to education and for them to benefit from peer collaboration that exists in more diverse classrooms. However, inclusive education is still not fully implemented in most nations given that different interpretations have been given to inclusion informing the model adopted in teaching CWSNs in regular classes in these countries (Braunsteiner \& Mariano-Lapidus, 2014; DudleyMarling \& Burns, 2014; Schuelka \& Johnstone, 2011). Some factors, including parental perceptions of CWSNs and the difficulties encountered in helping them, societal attitudinal problems and training inadequacy of stakeholders, have been adduced for the persistent exclusionary practices in handling CWSNs in regular schools (Limaye, 2016). Purdue (2009) had reported that there is the tendency of the education of CWSNs in regular classrooms to be sacrificed to the education of children without special needs when it is perceived to be challenging and perceived to interfere with the education of regular children. Respondents were of the view that such children should be educated in a segregated learning environment (Purdue, 2009).

Literature indicates that teachers may be unwilling to embrace inclusive education of CWSNs and they are likely to be rejected by teachers (Cook \& Cameron, 2010; Lalvani, 2002; Purdue, 2009; Rieser, 2013). Other studies have shown that teachers could have preferences to the cohort of CWSNs they are willing to accept resulting in attitudinal bias when presented with the children (Cassady, 2011). For Cassady (2011) the nature of disability is likely to affect the receptivity of a child and this could lead to teachers not providing the necessary support that could bolster the development of the child with special needs. This is in line with the thought that teachers' willingness is a crucial variable to effectively work with CWSNs in regular classrooms (Low, Ng, Hui, \& Cai, 2019). Low, et al (2019) in recognition of the fact that challenges teachers face in educating CWSNs impact on the well-being of the teachers and students, have suggested that efforts should be made to adopt a positive approach that will aim at identifying facilitative factors that enable teachers brave the challenges. Research in this direction will likely contribute to mounting effective intervention programme in both pre-service and in-service level of teacher practice for teachers to adopt inclusivity in regular classes. Studies looking at teachers' willingness to teach CWSNs are inadequate to explain factors that will predict teachers' willingness (Low, et al 2019). This led Low, et al (2019) to investigate how teachers' affective and cognitive selfconcept impact on teachers' willingness to teach children with special needs. Self-concept is an important variable in teacher education in the sense that it can reveal the true picture of the 'teacherself within the domain of teaching profession. Gilor and Katz (2018) built a model explaining preteachers' willingness to teach in an inclusive education setting by leveraging on their belief variables, attitude, perceived self-efficacy and subjective norms with regards to inclusivity.

Our study intends to extend Low's et al (2019) study by integrating teachers' empathy into the model to explain its mediation power on the association between teachers' self-concept and their willingness to teach and provided emotional and adaptive support to children with special needs. We intend to demonstrate how teacher empathy could mediate their self-concept and their inclusion willingness. This is predicated on the fact that 'empathic teachers are revealed as highly moral individuals who attach themselves mentally and emotionally to their students and generate similar responses in return' (Cooper, 2004: 12). Teachers who have CWSNs in their classes have been reported to score higher in empathy scales (Kourmousi, et al, 2017). Though the extant literature reveals a paucity of studies investigating whether teachers' empathy and their self-concept will likely predict their willingness to accepting CWSNs in their regular classrooms, we assume that the predictive power of teacher self-concept on their willingness to accept CWSNs in their regular classes could be mediated by their empathy. This arose from the fact that one's perception of self in a profession is likely to impact on his behaviours in such professional context.

\section{Literature Review}

\subsection{Conceptualizing Students with Special Needs and their Education in Nigeria}

There are disagreements on who students with special needs are, leading to referring them to as 'at- 
risk children', 'challenging children', 'additional needs' or children with disabilities (Drabble, 2013; Low, et al, 2019; Norwich, 2016). There have been a number of reasons advanced for the choice of the terms underpinned by varying social understanding (Drabble, 2013). Low, et al (2019) have noted that they adopted challenging children based on the fact that 'at-risk' may convey a less positive perspective. However, special needs as a term is rooted on the fact that every child has his uniqueness and for his/her needs to be met, efforts are made to avoid a mismatch between the individual need and support provided (Norwich, 2016). This could connote the essence of the efforts teachers are likely to make to help children in this category.

Researchers are of the view that students with special needs include those with normative and non-normative difficulties (Drabble, 2013). For Drabble (2013) normative difficulties are the difficulties that have an organic origin and can easily generate consensus of professionals while the non-normative difficulties may not be linked with organic origin but could be linked with the child's socio-economic background and other vulnerable environmental attributes and many researchers do not agree on what makes up this category. This latter category may not be regarded as the hard core difficulties. Students with special needs have been described as children with various exceptionality (Federal Ministry of Education (FME), 2015). Exceptionality in this context refers to children that need additional support to succeed in school. Therefore, students with special needs in the context of this study is conceptualized as children who their teachers may see as needing additional support to succeed in school, the origin of the difficulties notwithstanding.

Nigeria is a signatory to most International Declarations and Conventions that have to do with equalization of opportunities for persons with disabilities and their rights to education. Nigeria has a National Policy on Education which has been reviewed severally to align her educational objectives and policies with the changing dynamics of the society and also for the citizenry to be prepared for global competitiveness. This National Policy directs every other policy within the educational system (UNICEF, Nigeria, 2011). There is a provision for the education of persons with disabilities in an inclusive setting (Federal Republic of Nigeria (FRN), 2013) even though it was sketchy and may not necessarily serve as a comprehensive document for effective implementation of inclusive education. This might have resulted in the National Policy on Special Needs Education in 2015 (FME, 2015). This document was a result of the challenges encountered in the education of children with special needs. It recognized that there was a problem with conceptualization of inclusive education, inadequate manpower and facilities in schools to cater for CWSNs though the bulk of services rendered to CWSNs are done within the school environment (FME, 2015). Researchers have observed that practices in educating CWSNs in Nigeria are below international best practices, negating the principles of inclusive education (Adetoro, 2014). Educating CWSNs in regular classes in Nigeria has faced a number of prohibitive factors even when teachers may be willing to accept these children in their classes. Nigerian teachers have been found to be in favour of teaching CWSNs in regular classes though some are of the opinion that the regular classrooms are not friendly enough to accommodate them in schools; and that they are not equipped with the competence to handle and cope with the challenges of CWSNs (Olukotun, 2015). A similar study using a sample of children with albinism in Nigeria has shown that the learning environment is not friendly for the students (Nwosu, Unachukwu, Nwasor, \& Ezennaka, 2019). Inadequate training, disability unfriendly learning environment and policy problems may conspire to affect the willingness of teachers to accept CWSNs in regular classes (Osero, 2015). It becomes pertinent to understand the psychological variables that can explain teachers' willingness to accept CWSNs in the classes especially in a Nigerian context.

\subsection{Teacher self-concept and teaching children with special needs}

Research focusing on belief systems has indicated how an individual's belief system, self-concept inclusive, could affect his/her attitude, ability, and behaviour (Stojiljković, Todorović, Đigić, \& Dosković, 2014; Yeung, Craven, \& Kaur, 2014). Individuals have a way of seeing their competence within 'domains of functioning' (Low, et al, 2019:21). In the context of the teaching profession, researchers are 
of the view that teachers' self-belief system can impact on the teaching and their perceptions of their students' learning abilities (Yeung, et al, 2014). Higher teacher self-concept has been linked with productive teacher outcomes and prosocial behaviours. Stojiljković, et al (2014) found a significant positive relationship between teachers' self-concept and their empathic sensitivity. On teachers' effectiveness, researchers have found a positive significant relationship between teacher self-concept and teacher effectiveness in their professional roles (Diem 1998; Sawney \& Mangat, 2015; Zlatkovic, Stojiljković, Djigic, \& Todorović, 2012). Studies on teacher self-concept in the context of inclusive education is still lacking. However, Low, et al (2019) in their study demonstrated that teacher affective and cognitive self-concepts are predictors of the willingness to teach children with special needs. Since, teacher concept has been seen to underscore teachers' prosocial behaviours and professional effectiveness, we argue that its impact on teachers' willingness to include CWSNs in their regular classrooms could be mediated through teacher empathy.

\subsection{Teachers' empathy and receptivity of children with special needs}

Inclusivity entails openness to diversity in such a way that individual needs of all are attended to. Overall, there has been the need for teachers and stakeholders to be receptive of the uniqueness each child presents in the classroom in such a manner that all children are given equal opportunities to develop. Researchers have documented the challenges teachers encounter in handling CWSNs (Olukotun, 2015; Osero, 2015). To brave these challenges, teacher empathy becomes inevitable to work with these children. Given this importance, Bouton (2016) sees teacher empathy as an essential socioemotional trait that must be cultivated among teachers starting from their teacher education training.

Empathy is a new field of study in education and has been defined in the context of education as 'the ability to interpret stress or pleasure with effortful control' (Boyer, 2010 as cited by Bouton, 2016:18). De Klerk and De Klerk (2018:658) aptly defined empathy as 'one's ability to put oneself in another's emotional and cognitive situation, and act accordingly with support and understanding'. Drigas and Papoutsi (2015) see empathy as a 'complex form of psychological inference in which observation, memory, knowledge, and reasoning are combined to yield insights into the thoughts and feelings of others' (p. 37), allowing individuals the understanding and inference of others' feelings, behaviours and emotions. For de Klerk and de Klerk (2018), practising inclusive education entails teacher empathic sensitivity though inadequate literature exists regarding this; while Partridge (2018) sees empathy as one of the ways through which diversity in classrooms is appreciated.

Positive behavioural outcomes have been linked to teacher empathy given its place in interrelationships (Young, 2016). Research has shown that empathic climate has a positive effect on students' achievement in mathematics and self-concept (Buckley, 1993). Research on teachers' attitude towards inclusive education, has shown that emotional empathy is significantly related to teachers' attitude towards inclusive classrooms (Navarro-Mateu, Franco-Ochoa, Valero-Moreno, \& Prado-Gasco, 2019) while positive attitude towards persons with disabilities has been linked to a higher level of student teachers' empathy (Barr, 2013). Consistent with extant literature is the fact that teachers' empathy is linked to a positive attitude to inclusion and productive and a cordial relationship with their students with special needs. We argue here that if teachers' empathy could result to a positive attitude to inclusive education and CWSNs that it could also be linked with their willingness to accept CWSNs in their regular classes.

\section{Objectives and Hypotheses}

We set out to fit the conceptual model in which we try to demonstrate how teachers' self-concept, and teacher empathy explain teachers' willingness to teach students with special needs in Nigerian regular classrooms. It was also our aim to determine the mediating effect of teacher empathy on the association existing between teachers' self-concept and their willingness to include CWSNs in their regular classes. We, therefore, hypothesized that: 
a. The empirical data would significantly fit the conceptual model.

b. Teachers' self-concept (affective and cognitive) would significantly have direct effects on teacher self-empathy, and their willingness to include (teach and provide emotional and adaptive support) CWSNs in their regular class classes.

c. Teacher empathy would not significantly mediate the association between teachers' selfconcept (affective and cognitive), and their willingness to include (teach and provide emotional and adaptive support) CWSNs in their regular class classes.

\section{Method}

\subsection{Research Design}

The correlational research design was adopted as a research design for our study. The two dimensions of teacher self-concept constituted the exogenous variables and the teacher empathy and teacher selfconcept and willingness to include CWSNs in regular classes made up of the endogenous variables. Teacher empathy served as a mediator variable. We built an empirical model and also sought to ascertain the direct and indirect effect. Hence, we adopted path analysis. Given that available literature showed that teacher empathy and self-concept could influence prosocial and care behaviours, we hypothesize that the exogenous variable will have a direct and an indirect effect on the dependent variable.

\subsection{Participants}

Three hundred and sixteen teachers in Awka South Local Government Area of Anambra State made up the sample size of our study. These are teachers who teach in public schools. Our respondents were sampled using a convenience sampling technique. Copies of the questionnaire were distributed at the 15 secondary schools sampled for the study. Out of the 317 teachers given the copies of the questionnaire only one teacher dropped out of the study and did not complete the filling of the questionnaire. Hence, our final sample size was 316. Socio-demographic variables of our respondents showed that $79.4 \%$ were female teachers while $20.6 \%$ were male teachers; $61.1 \%$ were married, $38.9 \%$ were not married while o\% were windowed.

\subsection{Instruments}

We used three instruments in the study. The first is the Teacher Self-concept Questionnaire (TScQ) adopted from the works of Low, et al (2019). The TScQ has two clusters of Teacher Affective Selfconcept (TASc) and Teacher Cognitive Self-concept (TCSc). This instrument was developed by Low, et al (2019) for a larger study after an extensive literature search. They reported that the two clusters had high internal consistency coefficients. We used the dimensions of the instrument as the independent variables in the study.

The second instrument is the Toronto Empathy Questionnaire (TEQ) developed by Spreng, McKinnon, Mar and Levine (2009). It is a one-dimensional scale containing 16 items scaled as never = $\mathrm{o}$, rarely $=1$, sometimes $=2$, often $=3$, always $=4$. It assesses emotion as an emotional process and not as a cognitive process. Of the 16 items, items 2, 4, 7, 10, 11, 12, 14 and 15 are scored in reverse order. The psychometric properties of TEQ have been determined cross-culturally. Among Turkish students and Greek teachers it has high internal consistency index and stability coefficient and has been confirmed. (Kourmousi, et al, 2017; Totan, Doğan, \& Sapmaz, 2012).

The third instrument was an integration of the Teacher Willingness to Teach Challenging Children Questionnaire (TWTCCQ) (Low, et al, 2019) and the behavioural component of the Teachers' Multidimensional Attitude towards Inclusive Education Scale (TMATIES) (Mahat, 2008). We had the intention of broadening the concept to include aspects that will entail emotional support and flexibility in teaching. We, therefore, would refer to the questionnaire here as Teacher Willingness to Include CWSNs Questionnaire (TWICSNQ). EFA conducted on showed it consists of two factors. 
Researchers collected data from teachers in public schools through direct delivery technique in which they went to the schools and explained to the teachers the essence of the research. Teachers were told that the exercise is purely for research purposes and their responses would be kept confidential. Teachers were allowed to pull out of the study any time they deemed fit. Teachers who were busy at the time of the distribution of the questionnaire but agreed to participate in the study were given time to finish their duties first before filling in the questionnaire.

The main analysis was preceded by testing of statistical assumptions. First, we conducted a test to determine the adequacy of the sample size before the empirical model fit. Our hypothesized model had 9 distinct parameters with a sample size of 316 amounting to a ratio of 35:1. This is within the acceptable cut off by Kline (2011). Kline had stated that sample size-to-parameter be estimated at 10:1, even though it could be better estimated at 20:1. Second, we used the regression imputation default in SPSS Amos to handle the missing values. A complete data-set was generated for the analysis. Third we checked the univariate and multivariate normality of the distribution to eschew significant deviation from normality. The univariate normality was based on the values of Skewness and kurtosis. All the distributions were all normally distributed. Kline (2011) recommended that skewness values should be $\leq 3$ while kurtosis should be $\leq 10$. Multivariate normality test indicated that the value of kurtosis is 24.287 showing a substantial departure from the norm since the value of the kurtosis is greater than 5 . However, the Bollen-Stine bootstrap p $=.154$ indicated that the model is fit. See table 1.

Table 1. Normality Test of the Variables

\begin{tabular}{|c|c|c|c|c|c|c|}
\hline Variable & minimum & maximum & Skewness & c.r. & kurtosis & c.r. \\
\hline Teacher affective self-concept & 4.000 & 16.000 & -.845 & -6.133 & .189 & .685 \\
\hline Teacher cognitive self-concept & 6.000 & 16.000 & -.915 & -6.637 & .439 & 1.594 \\
\hline Teachers' empathy & 12.000 & 38.000 & -.505 & -3.666 & .171 & .619 \\
\hline Willingness for emotion and adaptive support & -.950 & 3.062 & 1.496 & 10.860 & 12.661 & $45 \cdot 943$ \\
\hline $\begin{array}{l}\text { Willingness for teaching support } \\
\text { Multivariate }\end{array}$ & -1.486 & 1.924 & .097 & .703 & $\begin{array}{c}1.374 \\
24.287\end{array}$ & $\begin{array}{l}4.986 \\
25.801\end{array}$ \\
\hline
\end{tabular}

\section{Results}

\subsection{Preliminary Analysis of Relationships and Means}

Table 2: Variable Relationships, Mean Scores and Standard Deviation ( $\mathrm{N}=316)$

\begin{tabular}{|c|c|c|c|c|c|}
\hline & $\begin{array}{l}\text { Teacher } \\
\text { affective } \\
\text { self- } \\
\text { concept }\end{array}$ & $\begin{array}{l}\text { Teacher } \\
\text { cognitive } \\
\text { self- } \\
\text { concept }\end{array}$ & $\begin{array}{l}\text { Teacher } \\
\text { empathy }\end{array}$ & $\begin{array}{c}\text { Willingness to } \\
\text { teach children } \\
\text { with special } \\
\text { needs }\end{array}$ & $\begin{array}{c}\text { Willingness for } \\
\text { emotional and adaptive } \\
\text { support for children with } \\
\text { special needs }\end{array}$ \\
\hline Teacher affective self-concept & 1 & & & & \\
\hline Teacher cognitive self-concept & $.638^{* *}$ & 1 & & & \\
\hline Teacher empathy & .114 & $.200^{* *}$ & 1 & & \\
\hline Willingness to teach children with special needs & $.319^{* *}$ & $.321^{* *}$ & $.230^{* *}$ & 1 & \\
\hline $\begin{array}{l}\text { Willingness for emotional and adaptive support } \\
\text { for children with special needs }\end{array}$ & $.247^{* *}$ & $.334^{* *}$ & $.290^{* *}$ & $.573^{* *}$ & 1 \\
\hline Mean & 13.33 & 13.86 & $25 \cdot 94$ & 12.12 & 19.42 \\
\hline Standard Deviation & 2.64 & 2.21 & 4.50 & 2.25 & 3.02 \\
\hline
\end{tabular}

Table 2 showed that teacher affective self-concept is positively and significantly related to teachers' willingness to teach and provide emotional and adaptive support to CWSNs in their regular classes (p.<.05), but non-significantly related to teachers' empathy. More so, teacher cognitive self-concept is 
positively and significantly related to teachers' willingness to teach and provide emotional and adaptive support to CWSNs in their regular classes (p.<.05), and to teachers' empathy (p.<.05). Teacher empathy was significantly and positive related to teachers' willingness to teach and provide emotional and adaptive support to CWSNs in their regular classes.

\subsection{Measurement Models}

For the fact that we conducted a multifactorial analysis, we used confirmatory factor analysis in conducting the measurement models of the three instruments used in the study using SPSS Amos version 24. The essence of this is to ascertain the fits of the instruments among Nigerian teachers. We adopted a factor loading of .04 which was considered acceptable (Garson, 2010, as cited in CabreraNguyen, 2010) and there was item reduction in only one of the instruments: TEQ. For TScQ all the items were retained given that they loaded above .40 as presented in figure 1 :



Figure 1: TScQ CFA model

Because TEQ had lower factor loading, there was item reduction. Ten items were retained. Two of the items had factor loadings below .40 and were retained because the model indices were fit and the items are theoretically meaningful. Hence there was no need to reduce the items to $50 \%$. The factor loadings are presented in figure 2 :

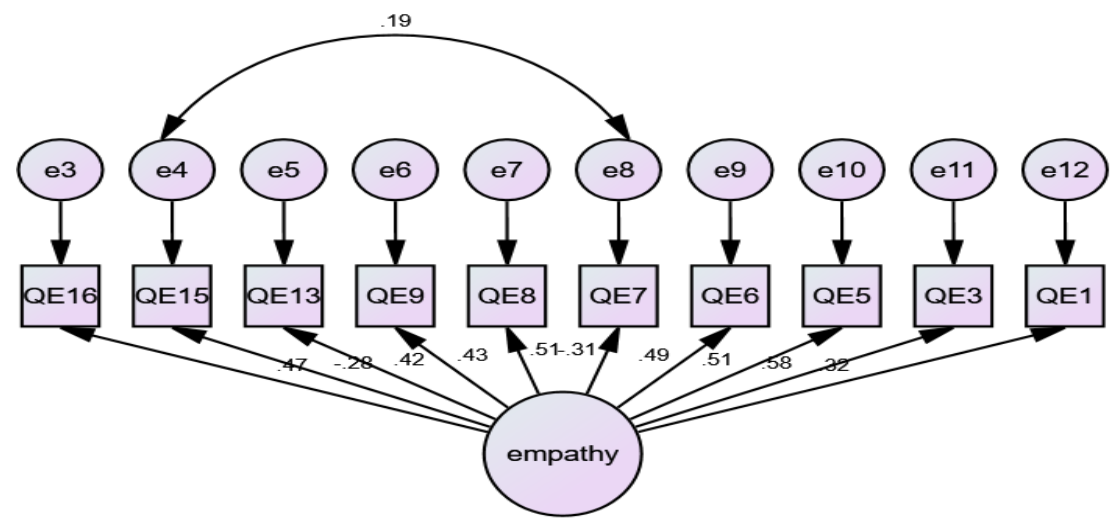

Figure 2: TEQ CFA model

Given that we added six additional items to TWICSNQ, an exploratory factor analysis (EFA) with principal axis factor analysis with varimax rotation was conducted before the CFA. This was to 
determine the underlying structure of the 10-item TWICSNQ. We checked the missing data, correlation matrix and the interrelationships ranged between $>.20$ and $<.57$; the determinant was $<.00001$ and >0, Kaiser-Meyer-Olkin (KMO) measure was .882, the Bartlett test of sphericity was significant at 0.000 indicating that the variables are highly correlated providing a justifiable basis for factor analysis. The Communalities table shows the Initial commonalities were above .30. The Total Variance Explained table shows how the variance is divided among the 10 possible factors and two factors have eigenvalues greater than 1.o.

Rotation showed the first factor accounted for $25.64 \%$ of the variance, the second factor accounted for $21.21 \%$. All the items were well loaded and had loadings $>.50$. Closer examination of the items shows that factor 1 is for teaching support for CWSNs while factor $\mathbf{2}$ is for emotional and adaptive support as presented in table Appendices A and B. We thereafter conducted the CFA presented in figure 3.

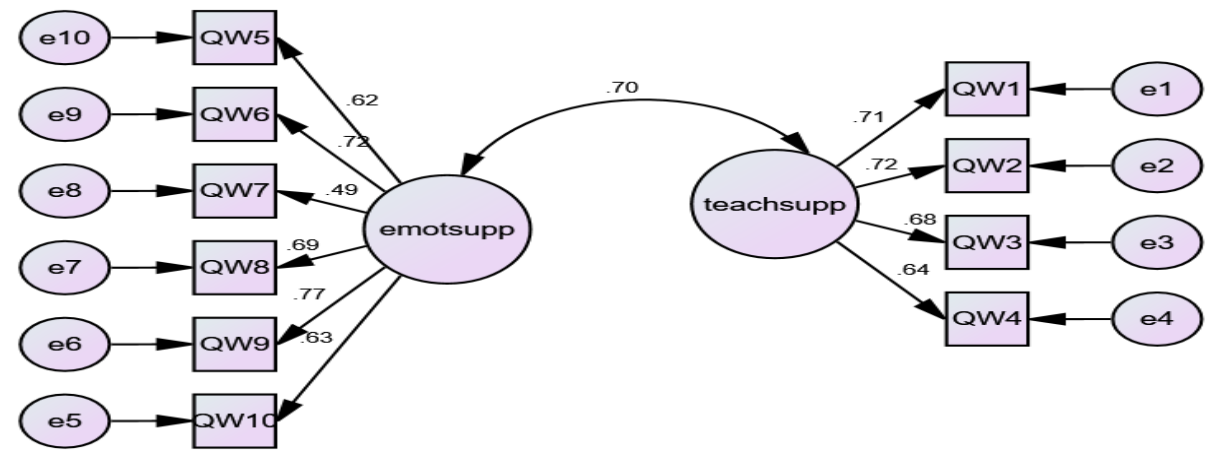

Figure 3: TWICSNQ CFA model

The CFA model fit indices of the instruments showed that they were fit except for TEQ that showed marginal fit as presented in table 3 .

Table 3. CFA Model Fit of the Instrument

\begin{tabular}{lccccccc}
\hline Measurements & $X^{2}$ & $D f$ & $R M S E A$ & GFI & CFI & NFI & TLI \\
\hline Teacher self-concept (Two-dimensional) & $35 \cdot 350^{* *}$ & 17 & .059 & .973 & .989 & .980 & .983 \\
Teacher Empathy (one-dimensional) & $55.307^{* *}$ & 34 & .045 & .967 & .935 & .852 & .914 \\
Willingness to Include CWSNs (two-dimensional) & $71.019^{* *}$ & 34 & .059 & .957 & .964 & .934 & .952 \\
\hline
\end{tabular}

\subsection{Hypothesized structural model fit indices}

We assessed the model fit with a number of fit indices. They are: Chi-square and degree of freedom, the comparative fit index (CFI), goodness-of-fit index (GFI), the incremental fit index (IFI), the normed fit index (NFI), the Trucker Lewis Index (TLI), root mean square error of approximation (RMSEA). Results showed that GFI, TLI, CFI, NFI has a value of .997, .975, .997, and .996 respectively showing that hypothesized model fit adequately to the data (value $>0.90$ is a good fit). The Root Mean Square Error of the Approximation (RMSEA) is .068 (values $<0.08$ is a good fit), the ratio of Chi-square to degrees of freedom is 2.447 which is less than 5 indicating a good fit. The indices show that final hypothesized model fit the data adequately. 


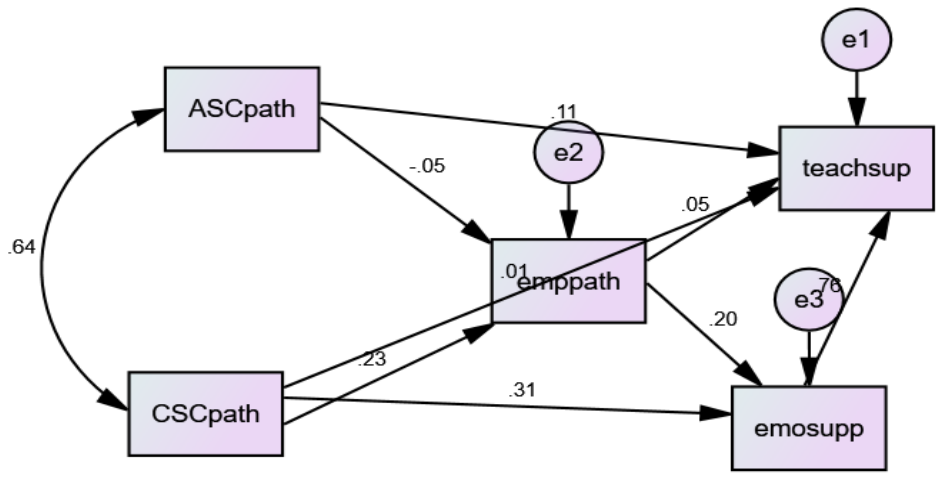

Note: ACSpath=teacher affective self-concept, CSCpath=teacher cognitive self-concept, emppath=teachers empathy, emosupp=willingness for emotional and adaptive support, teachsup=willingness to teach.

Figure 4. Empirical model fit of the variables

\subsection{Direct Impacts of Exogenous variables on Endogenous Variables}

The full structural model was preceded by hypothesizing that teacher affective and cognitive selfconcepts would have significant effects on their willingness to include CWSNs in their regular classrooms. The result showed that teacher affective self-concept has no significant positive direct effect on their willingness for emotional and adaptive support $(\beta=.096, P>0.05)$, but a significant positive direct effect on their willingness to teach $(\beta=.182, P<0.05)$. Teacher cognitive self-concept has a significant positive direct effect on their willingness for emotional and adaptive support $(\beta=.299$, $P>0.05)$, and also a significant positive direct effect on their willingness to teach $(\beta=.253, P<0.05)$. Then the direct effects on the full model are shown in the table.

Table 4: Regression Weights, Probability Values of the Variables of the Model

\begin{tabular}{|c|c|c|c|c|c|c|}
\hline \multirow{2}{*}{\multicolumn{2}{|c|}{ Parameter }} & \multirow{2}{*}{ Estimate } & \multirow{2}{*}{ SE } & \multicolumn{2}{|c|}{$95 \% C I$} & \multirow{2}{*}{$\mathrm{P}$} \\
\hline & & & & Lower & $\overline{\text { Upper }}$ & \\
\hline Teacher empathy & <--- Teacher cognitive self-concept & .234 & .146 & .082 & .368 & .002 \\
\hline Teacher empathy & <--- Teacher affective self-concept & -.051 & .123 & -.170 & .096 & .433 \\
\hline Willingness for emotional and adaptive support & $<---$ Teacher empathy & .204 & .004 & 101 & .302 & .001 \\
\hline Willingness for emotional and adaptive support & <--- Teacher cognitive self-concept & .313 & .009 & .209 & .419 & .001 \\
\hline Willingness to Teach & <--- Teacher empathy & .049 & .003 & -.021 & .127 & .195 \\
\hline Willingness to Teach & $<---$ Teacher cognitive self-concept & .014 & .009 & -.075 & .099 & .741 \\
\hline Willingness to Teach & $<---$ Teacher affective self-concept & .109 & .007 & .020 & .207 & .014 \\
\hline Willingness to Teach & $<---$ Willingness for emotional and adaptive support & .758 & .040 & .685 & .812 & .001 \\
\hline
\end{tabular}

Table 4 showed teacher affective self-concept had a positive significant direct effect on teachers' willingness to teach CWSNs $(\beta=.109, P<0.05)$, and non-significant effects with teacher empathy $(\beta=-$ .051, $P>0.05)$. Teacher cognitive self-concept had a positive non-significant direct effect on teachers' willingness to teach CWSNs $(\beta=.014, P>0.05)$, and a positive significant direct effect with teacher empathy $(\beta=.234, P<0.05)$ and willingness for emotional and adaptive support $(\beta=.313, P<0.05)$. Teacher empathy had a significant direct effect on the willingness for emotional and adaptive support $(\beta=.204, P<0.05)$ and a non-significant positive direct effect on willingness to teach $(\beta=.049, P>0.05)$. Furthermore, teachers' willingness to offer emotional and adaptive support had a positive significant direct effect on their willingness to teach CWSNs $(\beta=.758, P<0.05)$. These are based on 1000 bootstrap sample at 95 bias-corrected confidence intervals. 
Table 5: Standardize Indirect Effects of the Exogenous Variable on the Endogenous Variables and Probability Values of the Variables in the Models

\begin{tabular}{|c|c|c|c|c|}
\hline \multirow{2}{*}{ Parameter } & \multirow{2}{*}{ Estimate } & \multicolumn{2}{|c|}{$95 \% C I$} & \multirow{2}{*}{$\mathrm{P}$} \\
\hline & & Lower & Upper & \\
\hline $\begin{array}{l}\text { Teacher affective self-concept on willingness for emotional and adaptive support } \\
\text { through teacher empathy }\end{array}$ & & -.036 & .020 & .374 \\
\hline Teacher affective self-concept on willingness to teach through teacher empathy & -.010 & -.036 & .020 & .374 \\
\hline $\begin{array}{l}\text { Teacher cognitive self-concept on willingness for emotional and adaptive } \\
\text { support through teacher empathy }\end{array}$ & .040 & .017 & .087 & .001 \\
\hline $\begin{array}{l}\text { Teacher cognitive self-concept on willingness to teach and adaptive support } \\
\text { through teacher empathy }\end{array}$ & .285 & .207 & .366 & .001 \\
\hline
\end{tabular}

Note: $\mathrm{CI}$ = confidence intervals; $\mathrm{LB}=$ lower bound; $\mathrm{UB}=$ upper bound; $\mathrm{SE}$ = standard error.

Table 5 Teacher cognitive self-concept had a significant indirect effect on willingness to teach and for emotional and adaptive support through teacher empathy based on 100 bootstrap sample at 95 biascorrected confidence intervals. Teacher affective self-concept had no significant indirect effects on willingness to teach and for emotional and adaptive support for CWSNs through teacher empathy.

\section{Discussion}

Our study aimed at testing an empirical model to understand what variables would explain teachers' willingness to include CWSNs in their regular classroom. The fit indices applied showed that the conceptualized model fits the data. This shows that for an understanding of teachers' willingness to include CWSNs in their regular classes, there is a need to take recourse to teacher belief and their socioemotional variables. These variables could influence teachers' interpersonal relationships with CWSNs and motivate them to support them not minding the challenges. Preliminary findings in our study showed that teachers scored higher in their cognitive self-concept than their affective self-concept. This shows that teachers perceive themselves more highly in their roles and competence in their profession than in their emotional attachment in their profession. This is a little bit in contrast with Low, et al (2019) findings that showed that teachers scored higher in their affective self-concept than in their cognitive self-concept. This could be accounted for by differences socio-cultural factors given that the way the teaching is viewed in a particular culture could impact on teacher belief systems and their attachment to the teaching profession. Teachers also showed higher scores in the empathy sensitivity and their willingness to include CWSNs in their class. Studies have shown that teachers are willing to teach CWSNs (Olukotun, 2015).

Our finding has shown that teacher affective and cognitive self-concepts are positively and significantly related to teachers' willingness to teach and provide emotional and adaptive support to CWSNs in their regular. Furthermore, teacher affective self-concept had a positive significant direct effect on teachers' willingness to teach CWSNs while teacher cognitive self-concept had a positive nonsignificant direct effect on teachers' willingness to teach CWSNs and a positive significant effect on willingness for emotional and adaptive support. The association between teacher self-concept and their willingness to include CWSNs in the regular classes found in this study is a reflection of previous findings that teacher self-concepts are linked to teacher effectiveness and prosocial behaviours (Diem 1998; Sawney \& Mangat, 2015; Zlatkovic, et al, 2012). This could have resulted from the fact that the way one perceives oneself in a profession will likely affect his behaviour and action (Stojiljković, et al, 2014; Yeung, et al, 2014). Those who positively perceive their importance in a profession is likely to go the extra mile to brave challenges such as teaching and caring for children with special needs. Our findings agree, in part, with that of Low, et al (2019) going by the fact that they found teacher affective selfconcept being a better predictor of teachers' willingness to teach children with special needs. This is also consistent with our findings. This might have resulted from the fact that inclusive education may 
require a great deal of emotional preparedness. Against our expectation in this study is the finding that teacher cognitive self-concept predicted teachers' willingness to provide emotional and adaptive support more than the affective self-concept. This could be explained going by the fact that in cognitive self-concept teachers become more aware of the competence and role as teachers. Those who scored more here are likely to have understood that their works do not just stop at teaching in the classroom but include motivating and encouraging children. This link between cognitive development and emotional-motivational support during the learning process is consistent with similar aspects in Feuerstein's (2006) theory on Mediated Learning Experience. Thus, teachers with a strong cognitive self-concept are also more likely to understand that CWSNs need more emotional support and flexibility in their education; aspects that Feuerstein, Feuerstein and Falik (2010) highlight in their conceptualisation of the shaping of modifying environments.

Teacher empathy was significantly and positively related to teachers' willingness to teach and provide emotional and adaptive support to CWSNs in their regular classes. Teacher empathy had a significant direct effect on willingness for emotional and adaptive support and a non-significant positive direct effect on willingness to teach. This agrees with findings that teacher empathy is linked with care behaviours (Young, 2016) and that the attitude of teachers to inclusive education is positively impacted by teachers' empathy (Navarro-Mateu, et al, 2019). More so teachers' empathy is linked with a positive attitude towards persons with disabilities (Barr, 2013). What this implies is that teachers who are empathy sensitive are more likely to work towards providing an academic atmosphere that is facilitative for children with special needs. Our finding that showed that empathy is a better predictor of teachers' willingness to provide emotional and adaptive support for special needs students than their willingness to teacher reflects the socio-emotional nature of empathy in which an individual not only understands the feel of another but is cognitively and emotionally ready to help out in such situation. This aligns with the fact that teacher affect is needed and those who provide emotional support for CWSNs are likely to engage in teaching them. This is supported in our model which showed that teachers' willingness to offer emotional and adaptive support had the most direct effect on their willingness to teach CWSNs than any other variable.

Teacher cognitive self-concept had a significant indirect effect on willingness to teach and for emotional and adaptive support through teacher empathy. What this means is that teachers who have higher cognitive self-concept are likely to have higher empathy which will culminate in their providing emotional/adaptive support and teach CWSNs in their classrooms. It is likely that this self-perception centering on competence and arouse teacher empathy leading to his/her taking an action geared towards inclusive education practice. On the other hand, teacher affective self-concept had no significant indirect effects on willingness to teach and for emotional and adaptive support for CWSNs through teacher empathy. This entails that the direct effect that teacher affective self-concept had on their willingness to teach CWSNs was not mediated. With adequate teacher affective self-concept, a teacher may likely teach CWSNs in regular classes. This might have accounted for why Low, et al (2019) found that teacher affective self-concept was a better predictor of teacher willingness to teach challenging behaviours than the cognitive self-concept.

\section{Conclusion}

Our study has provided a model to explain how the association between teacher self-concept and their willingness to include CWSNs in their regular classes could be mediated by their empathy. We have built on existing literature showcasing the importance of teacher self-concept and empathy are in the inclusive education practices. Willingness for inclusion is likely to be influenced by teacher belief system and socio-emotional characteristics indicating that teacher training should include sessions that will encompass ideas to improve their belief in the profession and also improve their empathetic sensitivity. Teacher training and even in-service training should include deliberate efforts for emotional intelligence and prosocial training.

Though we have investigated an important area in inclusive education practice especially in a 
developing country where inclusive practices are still not well implemented, our study is limited by the following reasons. First, there could be a significant gender bias given that our sample is made up of more female teachers than male teachers. This may limit the generalizability of our findings. Second, the study was a quantitative study only, a mixed-method approach will lead to more generalizability of the finding. Third, the TEQ had a marginal internal consistency index and a number of the items loaded poorly among the respondents even though the items were theoretically relevant. This shows the need for a locally constructed instrument among Nigerian teachers.

\section{References}

Adetoro, R. A. (2014). Inclusive education in Nigeria-A myth or reality? Creative Education, 5, 1777-1781. http://dx.doi.org/10.4236/ce.2014.520198

Barr, J. J. (2013). Student-teachers' attitudes toward students with disabilities: Associations with contact and empathy. International Journal of Education and Practice, 1(8), 87-100. doi: 10.18488/journal.61/2013.1.8/61.8.87.100

Bouton, B. (2016). Empathy research and teacher preparation: Benefits and obstacles. SRATE Journal, 25(2), 16-25.

Braunsteiner, M-L. \& Mariano-Lapidus, S. (2014). A perspective on inclusion: Challenges for the future. Global Education Review, 1 (1), 32-43.

Buckley, F. (1993). Empathic climate and learning outcomes: A study of teaching empathy in relation to mathematics learning outcomes (Doctoral dissertation, Dublin City University)

Cassady, J. M. (2011). Teachers' attitudes toward the inclusion of students with autism and emotional behavioral disorder. Electronic Journal for Inclusive Education, 2 (7), 1-24.

Cook, B. G. \& Cameron, D. L. (2010). Inclusive teachers' concern and rejection toward their students: Investigating the validity of ratings and comparing student groups. Remedial and Special Education, 31 (2), 67-76. doi: $10.1177 / 0741932508324402$

Cooper, B. (2004). Empathy, interaction and caring: Teachers' roles in a constrained environment. Retrieved from: https://www.google.com/search?client=firefox-b

$\mathrm{d} \& \mathrm{q}=$ oppimateriaalit.jamk.fi+\% $\% 2 \% 80 \% \mathrm{BA}+$ edusociety+\%E2 $\% 80 \% \mathrm{BA}+\mathrm{files}+\% \mathrm{E}_{2} \% \quad$ o\%BA+2010\% $\%$ Fo6 (October 16, 2020)

Diem, C. D. (1998). Teacher self-concept and teacher effectiveness as perceived by teachers of english and students of senior high schools. Jurnal Ilmu Pendidikan, 5(3), 154-166 doi: 10.17977/jip.v5i3.1039

Drigas, A. S. \& Papoutsi, C. (2015). Empathy, special education and ICTs. iJES, 3 (4), 37-42. http://dx.doi.org/10.3991/ijes.v3i4.5192

Dudley-Marling, C. \& Burns, M., B. (2014). Two perspectives on inclusion in the United States. Global Education Review, 1 (1), 14-31.

Federal Ministry of Education (FME). (2015). National Policy on Special Needs Education in Nigeria. Retrieved from http://planipolis.iiep.unesco.org/sites/planipolis/files/ressources/nigeria_special_needs_policy.pdf (October $16,2020)$.

Federal Republic of Nigeria (FRN). (2013). National Policy on Education (6 ${ }^{\text {th }}$ ed.). Nigerian Educational Research and Development Council: Lagos.

Feuerstein, R., Feuerstein, R.S. \& Falik, L.H. (2010). Beyond Smarter: Mediated learning and the brain's capacity for change. New York, NY: Teachers College Press.

Feuerstein, R., Rand, Y. \& Feuerstein, R.S. (2006). You love me!! Don't accept me as I am. Jerusalem: ICELP Publications.

Gilor, O. \& Katz, M. (2018). Pre-service teachers' willingness to engage in inclusive teaching: An explanatory model. Journal of International Special Needs Education, 1-13. doi: 10.9782/17 ooo11

Imaniah, I. \& Fitria, N. (2018). Inclusive education for students with disability. SHS Web of Conferences 42. https://doi.org/10.1051/shsconf/20184200039

Kourmousi, N., Amanaki, E., Tzavara, C. Merakou, K., Barbouni, A., \& Koutras, V. (2017). The Toronto empathy questionnaire: Reliability and validity in a nationwide sample of Greek teachers. Social Sciences, 6 (62), 1-14. doi:10.3390/socsci6o20062

Lalvani, P. (2002). Rethinking disability and inclusive education: A teacher study group. Review of Disability Studies: An International Journal, 11(3), 1-17.

Limaye, S. (2016). Factors influencing the accessibility of education for children with disabilities in India. Global Education Review, 3 (3). 43-56 
Low, E., Ng, P., Hui, C., \& Cai, L. (2019). How do teacher affective and cognitive self-concepts predict their willingness to teach challenging students? Australian Journal of Teacher Education, 44(10), 18-34. Retrieved from https://ro.ecu.edu.au/ajte/vol44/issio/2

Mahat, M. (2008). The development of a psychometrically-sound instrument to measure teachers' multidimensional attitudes toward inclusive education. International Journal of Special Education, 23 (1), 82-92.

Navarro-Mateu, D., Franco-Ochoa, J., Valero-Moreno, S., \& Prado-Gasco,' V. (2019). To be or not to be an inclusive teacher: Are empathy and social dominance relevant factors to positive attitudes towards inclusive education? PLoS ONE, 14(12), 1-19. Retrieved from https://doi.org/10.1371/journal.pone.0225993

Norwich, B. (2016). Conceptualising special educational needs using a bio-psycho-social model in England: the prospects and challenges of using the International Classification of Functioning framework. Retrieved from https://www.researchgate.net/publication/311918509

Nwosu, K. C., Unachukwu, G. C., Nwasor, V. C., \& Ezennaka, A. O. (2019). Teaching children with albinism in Nigerian regular classrooms: An examination of the contextual factors. Journal of Advocacy, Research and Education, 6(2), 4-16. Retrieved from: http://www.kadint.net/journals_n/1572372657.pdf

Olukotun, J. O. (2015). Teachers'views on inclusion in regular schools in Ilorin West, Kwara, Nigeria. Proceedings of the 14th Biennial Conference of the International Association of Special Education. Retrieved from www.iase.org > 14th-Conference > 2015 Proceedings

Osero, P. O. (2015). Challenges teachers encounter in implementing inclusive education in public primary schools in Nyamira County, Kenya. International Journal for Innovation Education and Research, 3(3), 217-230.

Partridge, E. J. (2018). Empathy in inclusive classrooms: Exploring prosocial behaviour through children's academic writing skills. Electronic Thesis and Dissertation Repository. 5275. Retrieved from https://ir.lib.uwo.ca/etd/5275

Purdue, K. (2009). Barriers to and facilitators of inclusion for children with disabilities in early childhood education. Contemporary Issues in Early Childhood, 10(2), 133-143. http://dx.doi.org/10.2304/ciec.2009.10.2.133

Rieser, R. (2013). Teacher education for children with disabilities: Literature review. UNICEF REAP Project

Sawney, S. \& Mangat, P. K. (2015). Teacher effectiveness in relation to self-concept of secondary school teachers. Indian Journal of Educational Studies: An Interdisciplinary Journal, 2(1), 141-155.

Schuelka, M. J. \& Johnstone, C. J. (2011). Global trends in meeting the educational rights of children with disabilities: From international institutions to local responses. https://www.researchgate.net/publication/280860309

Spreng, R. N., McKinnon, M. C., Mar, R. A., \& Levine, B. (2009). The Toronto Empathy Questionnaire: Scale development and initial validation of a factor-analytic solution to multiple empathy measures. Journal of Personality Assessment, 91(1), 62-71. doi:10.1080/00223890802484381.

Stojiljković, S., Todorović, J., Đigić, G., \& Dosković, Z. (2014).Teachers' self-concept and empathy. Procedia - Social and Behavioral Sciences, 116, 875 - 879. Retrieved from https:/www.sciencedirect.com/science/article/pii /S1877042814003309/pdf?md5=eb82c80039eao65aa2aeo813765eb7o\&pid=1-s2.o-S1877042814003309-main.pdf

Totan, T., Doğan, T., \& Sapmaz, F. (2012). The Toronto Empathy Questionnaire: Evaluation of psychometric properties among Turkish university students. Egitim Arastirmalarl Eurasian Journal of Educational Research, 46, 179-198. Retrieved from https://www.researchgate.net/publication/287776084

UNICEF, Nigeria. (2011). Situation analysis of children and women in Nigeria: 2011 update. https://www.unicef.org/nigeria/publications_8467.html

Yeung, A. S., Craven, R. G., \& Kaur, G. (2014). Teachers' self-concept and valuing of learning: Relations with teaching approaches and beliefs about students. Asia-Pacific Journal of Teacher Education, 42(3), 305-320. https://doi.org/10.1080/1359866X.2014.905670

Young, H. (2016). Perceived Lack of Teacher Empathy and Remedial Classroom Conflicts (Doctoral dissertation, Nova Southeastern University). Retrieved from https://nsuworks.nova.edu/shss_dcar_etd/44.

Zlatkovic, B., Stojiljković, S., Djigic, G., \& Todorović, J. (2012). Self-concept and teachers professional roles. ProcediaSocial and Behavioral Sciences, 69 (2012), 377-384. doi: 10.1016/j.sbspro.2012.11.423 


\section{Appendix A}

Factor Loadings from Principal Axis Factor Analysis with Varimax Rotation for a Two-Factor Solution for the Teachers' Willingness to Include Students' with Special Needs Questionnaire

\begin{tabular}{|c|c|c|c|c|}
\hline \multirow[t]{2}{*}{$\mathrm{S} / \mathrm{N}$} & \multirow[t]{2}{*}{ Items } & \multicolumn{3}{|c|}{ Factor } \\
\hline & & 1 & 2 & Commonality \\
\hline QW1 & I am willing to teach behaviuorally challenging classes & & .636 & .505 \\
\hline $\mathrm{QW}_{2}$ & I wouldn't mind teaching academically weak children & & .694 & .545 \\
\hline $\mathrm{QW}_{3}$ & I am prepared to teach the naughtiest students & & .677 & .492 \\
\hline $\mathrm{QW}_{4}$ & I am ready to teach at-risk kids & & .547 & .377 \\
\hline QW5 & $\begin{array}{l}\text { I am willing to encourage students with disability to participate in all social } \\
\text { activities in regular classroom }\end{array}$ & .523 & & .331 \\
\hline QW6 & $\begin{array}{l}\text { I am willing to adapt the curriculum to meet the individual needs of all students } \\
\text { regardless of their ability }\end{array}$ & .521 & & .439 \\
\hline $\mathrm{QW}_{7}$ & $\begin{array}{l}\text { I am willing to include students with severe disability in the regular classroom } \\
\text { with the necessary support }\end{array}$ & 693 & & .551 \\
\hline QW8 & $\begin{array}{l}\text { I am willing to modify the physical environment to include students with a } \\
\text { disability in the regular classroom }\end{array}$ & .671 & & .486 \\
\hline $\mathrm{QW}_{9}$ & $\begin{array}{l}\text { I am willing to adapt my communication technique to ensure that all student } \\
\text { with emotional and behaviuoral disorder can be successfully included in regular } \\
\text { classroom }\end{array}$ & .737 & & .599 \\
\hline QWio & $\begin{array}{l}\text { I am willing to adapt the assessment of individual students for inclusive } \\
\text { education to take place. }\end{array}$ & .522 & & .359 \\
\hline
\end{tabular}

Note: Items adapted from Low, et al (2019) and Mahat (2008)

\section{Appendix B}

Scree Plot showing the two-factor components of TWICSNQ

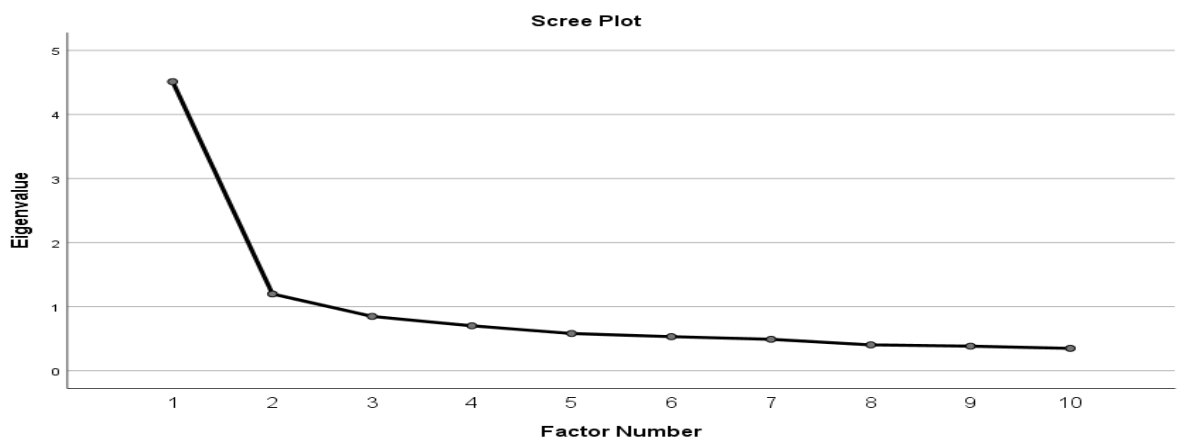

